\title{
How is Impact Factor Impacting Our Research?
}

\author{
Seema Rawat
}

The impact factor (IF) of an journal is a measure reflecting the average number of citations to recent articles published in the journal. It is frequently used as a proxy for the relative importance of a journal within its field, with journals with higher impact factors deemed to be more important than those with lower ones. However it is not a perfect metric and has its own limitations. Journals are increasingly finding new ways to improve their impact factor by increasing self citation, publishing more review articles. This correspondence discuss the fallacies of the impact factor. (Biomed J 2014;37:415-416)

\section{Key words: impact factor, research, publication}

A mong the various indexes that are currently used, the one that stands out as the most important index is the impact factor (IF). IF was devised by Eugene Garfield, the founder of the Institute for Scientific Information (ISI; now part of Thomson Reuters) as a way of quantifying the citation process. ${ }^{[1]}$ It is frequently used as a proxy for the relative prestige and quality of a journal within its field. IFs are calculated yearly for those journals included in the Thomson Reuters Journal Citation Report (JCR) data and show the average number of citations received in that year for each article published during the two preceding years.

The IF of a given journal for a year is calculated by dividing the number of citations in the previous 2 years by the total number of citable items in those 2 years. An IF of 1.5 for a journal means that papers received on average of 1.5 citations in Thomson Reuters ISI-listed journals in 2012. Citable items are research articles, case reports, technical notes, and review articles. Comments, editorials, and commentaries are usually not considered citable.

The IF has become an important metric for authors, universities, funding agencies, administrators, decision-making bodies, and editors, and is increasingly used for consideration of tenure and promotion and for budget and resource planning within universities, research institutions, and colleges. ${ }^{[2]}$ But it also can be misused by authors and researchers, with some calculating their own IF by adding the IF scores of the journals they have published in to create a personal IF.

The IF is not the perfect metric and has its own limitations. Only a minority of articles in a journal significantly contributes to the overall IF. There is great intra-journal variance in how often its papers are cited, making an average number such as IF truly flawed. Despite the limitations, IF has gained wide acceptance. The validity of the IF has even been questioned by various workers. This has happened because the index can, in a certain manner, be manipulated through strategies such as self-citation and increasing the allowed number of citations per article. Another point that has been criticized is that periodicals that publish greater numbers of review articles may obtain higher IFs than do those that only publish original articles. ${ }^{[3]}$

Journals frequently encourage self-citation at the expense of a balanced overview of the multidisciplinary literature. Some editors encourage review articles at the expense of publishing research findings. There is merit in publishing both kinds of articles, but that must be driven by good science and by what our readers want to see. The authors should cite the best available evidence or sources to ensure a quality product for readers. Medical Journals should encourages all kinds of submission and has no predilection for review articles and is fairly transparent in its publication policy. They should not succumb to the seductive lure of pursuing a high IF by employing policies targeted to inflate it. The IF has driven at least some journals to considerably alter their publication practices to increase IF. Such policies should be criticized.

IF is not the sole criterion for a scientific journal's success. It is an indicator of how often papers in a journal are cited by other papers. Thus, it only gives an idea of the scientific use of a journal and not necessarily its usefulness in clinical practice. Primary metric for success is whether

From the Department of Obstetrics and Gynaecology, Maulana Azad Medical College and Associated Lok Nayak Hospital, New Delhi, India Received: Sep. 02, 2013; Accepted: Apr. 14, 2014

Correspondence to: Dr. Seema Rawat, Department of Obstetrics and Gynaecology, Maulana Azad Medical College and Associated Lok Nayak Hospital, India. New Delhi - 110 001, India. Tel: 91-9868331408; Fax: 91-011-29942265; E-mail: drseemarawat@gmail.com

DOI: $10.4103 / 2319-4170.131388$ 
or not the membership values and reads its contents. For a journal, this is more important than IF. As said by its inventor, the American bibliometrician Eugene Garfield, the IF is not an absolute measure of the quality of a journal, but of its influence. ${ }^{[4]}$ Therefore, choosing the IF as an evaluation instrument equates to a decision to measure influence and not, or not primarily, quality. True, there should be a correlation between influence and quality, but it is difficult to agree on a definition of scientific quality.

Although some journals may show impressive increase in IF due to intense manipulations, others will disappear. Journals are now seeking to maximize their manipulation of the IF without getting "suppressed" from the IF list.

Researchers have started to look for journals with the highest IFs instead of journals with the best audience for their research. Journals with high IFs are now the desirable places to publish their research findings. Research fields and journals with lower IFs will get less funding and less authors/readers, and may subsequently lose their importance in the global scientific context, which may cause them to search for ways to boost the IF.

In the absence of a good alternative, the IF will continue to be used as an indicator of a journal's performance. It is high time that we stopped looking at IF as the measure of quality and find a new index which is more reliable and resistant to any manipulation.

\section{REFERENCES}

1. Garfield E. The history and meaning of the journal impact factors. JAMA 2006;295:90-3.

2. Baethge C. Impact factor-a useful tool, but not for all purposes. Dtsch Arztebl Int 2012;109:267-9.

3. Malathi M, Thappa DM. The intricacies of impact factor and mid-term review of editorship. Indian J Dermatol Venereol Leprol 2012;78:1-4.

4. Garfield E. Citation indexes for science a new dimension in documentation through association of ideas. Science 1995;122;108-11. 